\title{
Examination of Waste Management in Printing Industries using Electre-I Method
}

\author{
S. Bathrinath, A.K.N. Vignesh, S. Venkatesh, R. Satheshkumar
}

\begin{abstract}
In daily life, waste management is considered as one of the biggest issue faced by printing industry. When comparing with the other industries, the risk factors involved in printing industries are very high. Hence, it is necessary to find out the critical risk factors involved in waste management. In order to analyse this problem, Elimination and Choice Translating Reality (ELECTRE)-I, a Multi-Criteria Decision Making (MCDM) method is utilized. ELECTRE-I method is capable of providing solutions for the complex engineering problems. The ELECTRE-I is used to rank the printing industries associated with risk factors in waste management in printing industries. The result obtained will be helpful for the managers and practitioners working in printing industries.

Keywords: ELECTRE-I, MCDM, Printing industry.
\end{abstract}

\section{INTRODUCTION}

M ulti-Criteria Decision Making (MCDM), is an important technique that is widely preferred for solving complicated decision making problems. By using this method decision maker (DM) can easy to evaluate the problem in simplified manner. The pproblems involved with MCDM are perturbed with structuring, solving decision and planning. DMs can easily apply the MCDM method to obtain the solution related to the problem considered. DMs have their own preferences in the solutions, so there does not have a common solution for these problems. ELECTRE is one of the most widely used methods in multi-criteria decision analysis. ELECTRE (Elimination and Choice Expressing Reality) is applied for three main complications: choosing, ranking and arranging. ELECTRE was applied in two main areas likely construction of several outranking relations and profiteering policies. The ultimate aim of the work is to find factors for assessing waste management in printing industry. We approach some leading printing industries in Southern part of India; at last four printing industries accepted our proposal. The four printing industries respectively had given their own decision makers for our

Revised Manuscript Received on December 05, 2019.

* Correspondence Author

S.Bathrinath* Department of mechancical engineering, Kalasalingam Academy of research and education, Krishnankoil-626126, India. Email: bathri@gmail.com

A.K.N.Vignesh, Department of mechancical engineering, Kalasalingam Academy of research and education, Krishnankoil-626126, India. Email: akn1891997@gmail.com

S.Venkatesh, Department of mechanical engineering, Kalasalingam Academy of research and education, krishnankoil - 626126, India. Email: v9766766@gmail.com

R.Satheshkumar, Department of mechanical engineering, Kalasalingam Academy of research and education, krishnankoil-626126, India. Email: rsathesh3@gmail.com convenience, so the curiosity towards the ideology of our project makes us to do our best. So we have prepared questionnaire based on literature reviews and knowledge from industrial experts. The main part of this project is finding the factors, for that we discussed with the industrial experts, did some literature reviews and had a chat with the decision makers of a corresponding printing industries. As a result, we finalized totally of seven critical factors. The assessing of the factors of waste management in printing industries using ELECTRE-I has not been attempted in any of the literatures provided to the best of our knowledge. Waste management is one the biggest issue faced by printing industry in the last decade. In the printing industry, the risk factors are very high when compared with others. We explained the processes and find some factors and were given it to the decision makers of the industries to give rating for the factors. After obtaining the ratings from the decision makers a suitable MCDM practice is suggested to figure out the complication. Based on the complexity involved in the case considered, ELECTRE-I is proposed to solve this case. By using the ELECTRE-I, we rank the printing industries according to decision maker's rating of factors in waste management. Based on the lowest values in the table 4, we give suggestions to the industry for reducing the wastes.

\section{RELEVANT LITERATURE}

Relevant literature is sorted into three sub-sections namely (A) Factors for assessing waste management in printing industries (B) Use of MCDM tools (C) Literature gap

\section{A. Factors for assessing waste management in printing industries}

Haider et al. [1] evaluated the performance of two various sized water utilities using ELECTRE method. The results showed that this method is the best one, based on the minor changes of evaluations can't be established, when the preferences among different alternatives. Govindan and Jepsen [2] assessed the risk involved in supply chain using fuzzy numbers and ELECTRE TRI C. Informational and financial supply chain risks are the critical risks in the process. For this study they have a deep collaboration with the decision makers and the company. Pang et al. [3] evaluate an algorithm in a developed manner for a CNC machine. From earlier literature survey, it was identified that AHP and ELECTRE I method are widely used for problems comprising many criteria. Petrovic et al. [4] found that Material Selection for Bipolar Plates using ELECTRE I Decision Support Model. The outcomes demonstrated that the stuff collection problem of undulating trencher for PEFCs shows that 
ELECTRE I method is a suitable and efficient tool. Uysal and Yavuz [5] tried Multi-criteria ELECTRE method to the reflexing on tourism destination competitiveness. After all the pairwise comparison has taken place, the group of decisions has to be ranked according to ELECTRE I. Alemi et al. [6] study for a fuzzy environment under annexed of the Electre I method for class resolution-making. From the above study, the unreliability, vague and linguistic appraisals are the findings which are assessed by ELECTRE I method. Çosta et al. [7] explained an intuitionistic fuzzy environment under the tool of multi criteria decisions by integrating ELECTRE and VIKOR. The methodology helps the DMs to create pairwise and some sets to evaluate. Based on characteristics of IFS concordance and discordance sets created and it utilize ELECTRE.

\section{B. Use of MCDM tools}

Dodangh et al. [8] proposed MULTIMOORA method to integrate a weight-determining method. The results showed that the MULTIMOORA approach consider both weights and the preference of DMs.

\section{Literature gap}

Based on the literature survey, there is no sufficient amount of experimentation for detecting risk caused by waste management in printing organisations using MCDM methods. So as to fulfil this gap, this paper assesses the printing industries in South India based on risk factors related to waste management using an ELECTRE-I with the help of the Decision Makers (DMs) corresponding industries. The factors related to printing industries are identified based on the literature surveys and as well as inputs from industrial experts and they are presented in Table 1.

Table- I: Factors assessing waste management in printing industries

\begin{tabular}{|c|c|}
\hline Notations & Factors \\
\hline FAC $_{1}$ & Paper waste \\
\hline FAC $_{2}$ & Ferrous waste \\
\hline FAC $_{3}$ & Chemical waste \\
\hline FAC $_{4}$ & Film waste \\
\hline FAC $_{5}$ & Foils waste \\
\hline FAC $_{6}$ & PVC waste \\
\hline FAC $_{7}$ & Adhesive waste \\
\hline
\end{tabular}

\section{METHODOLOGY}

\section{A. ELECTRE-I}

The ELECTRE technique is used to analyze the source of a verdict matrix to outrank the relation theory. Based on capturing the decision maker's inputs in different domains, this method is the best outranking one. These outranking relations built in the way that the alternatives can be compared. In divergent ELECTRE method, concordance and discordance pair-wise comparison between alternatives are carried out. For reducing the decision makers subjectivity, ELECTRE-I method is used in this paper. Many researchers used ELECTRE-I for solving the problems $[9,10]$. The procedures of the ELECTRE-I are discussed below:

Step 1: Looking for expert views and identification of factors

A team of experts is formed and their ideas relevant to these topics are acquired. The factors for waste management are identified by inputs from industrial experts and also obtained from literatures.

Step 2: Design the linguistic rating

After the factor identification, it is essential to form a pairwise comparison matrix. By using the linguistic scale with five various values (Extreme high impact $=5$, very high impact $=4$, High impact $=3$, Low impact $=2$, Very low impact $=1$ ) the experts are assessing the interaction between different factor. By using linguistic scale, the experts are invited to provide rating for the development of pairwise-comparison matrix. The linguistic rating method shown in Table 2.

Table- II. Linguistic rating

\begin{tabular}{|c|c|}
\hline $\begin{array}{c}\text { Linguistic constants and their } \\
\text { description }\end{array}$ & Level of influence \\
\hline Extreme high impact (EH) & 5 \\
\hline Very high impact (VH) & 4 \\
\hline High impact $(\mathrm{H})$ & 3 \\
\hline Low impact (L) & 2 \\
\hline Very low impact (VL) & 1 \\
\hline
\end{tabular}

Step 3: Matrix Normalization and weighted matrix

For the normalized matrix $\mathrm{X}_{\mathrm{ij}}=\left[\mathrm{x}_{\mathrm{ij}}\right]$, the concepts on the interval numbers of decision matrix calculated by (1):

$$
x_{o p}=\frac{y_{o p}}{\sqrt{\sum_{o=1}^{z} y_{o p}^{2}}}, o=1,2, \ldots, q \quad p=1,2, \ldots, z
$$

The weighted matrix calculated according to normalized matrix assigned to it is given by:

$$
T_{o p}=E \times L=\left|\begin{array}{cccc}
e_{11} \cdot L_{1} & e_{12} \cdot L_{2} & \Lambda & e_{1 q} \cdot L_{q} \\
e_{21} \cdot L_{1} & e_{22} \cdot L_{2} & \Lambda & e_{2 q} \cdot L_{q} \\
\mathrm{M} & \mathrm{M} & \mathrm{O} & \mathrm{M} \\
e_{z 1} \cdot L_{1} & e_{z 2} \cdot L_{2} & \Lambda & e_{z q} \cdot L_{q}
\end{array}\right|
$$

Step 4: Validation of concordance and discordance interval sets

The concordance interval set is applied to describe the dominance query if the following condition is satisfied:

$$
c_{g h}=\left\{p \mid x_{g p} \geq x_{h p}\right\}
$$

Based on the concordance interval matrix, we obtain the discordance interval set using (4):

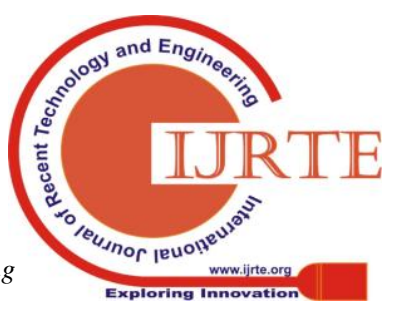




$$
D_{g h}=\left\{p\left|e_{g p}<\right| x_{h p}\right\}=J-V_{g h}
$$

(4)

Step 5: Establishment of the concordance interval matrix Concordance interval index $\left(\mathrm{C}_{\mathrm{ab}}\right)$ from $\mathrm{A}_{\mathrm{a}}$ to $\mathrm{A}_{\mathrm{b}}$ is calculated using (5):

$$
V_{g h}=\sum_{p \in V_{g h}} l_{p}
$$

Therefore, the concordance index signifies the preference of the argument "A outranks B". Finally, the concordance interval matrix is obtained as shown below:

$$
B=\left|\begin{array}{cccc}
- & b(1,2) & \Lambda & b(1, z) \\
b(2,1) & - & \Lambda & b(2, z) \\
\mathrm{M} & \mathrm{M} & \mathrm{O} & \mathrm{M} \\
b(z, 1) & b(z, 2) & \Lambda & -
\end{array}\right|
$$

(6)

Step 6: Computation of the Discordance interval matrix

Discordance index $\left(\mathrm{D}_{\mathrm{ab}}\right)$ can be prospected as the preference of discontent in decision of scheme $a$ rather than scheme $b$. Discordance interval matrix is represented as shown below:

$$
r(g, h)=\frac{\max _{p \in D_{a b}}\left|v_{g p}-v_{h p}\right|}{\max _{p \in P, z, q \in O}\left|v_{z p}-v_{q p}\right|}
$$

Normalized weight is calculated using the scheme $z, q$. By using discordance interval index sets, it is possible to compute discordance interval matrix as:

$$
R=\left|\begin{array}{cccc}
- & r(1,2) & \Lambda & r(1, z) \\
r(2,1) & - & \Lambda & r(2, z) \\
\mathrm{M} & \mathrm{M} & \mathrm{O} & \mathrm{M} \\
r(z, 1) & d(z, 2) & \Lambda & -
\end{array}\right|
$$

Step 7: Establish the concordance index matrix

Concordance index matrix can be represented using the equation given below:

$$
\bar{c}=\sum_{g=1}^{z} \sum_{h}^{z} v(g, h) / z(z-1)
$$

Here $\bar{v}$, the critical value can be resolved using average dominance index and the Boolean matrix $(\mathrm{E})$ is given by:

$$
\left\{\begin{array}{lll}
s(g, h)=1 \quad \text { if } & b(g, h) \geq \bar{v} \\
s(g, h)=0 & \text { if } & b(g, h)<\bar{v}
\end{array}\right.
$$

Step 8: Calculate the discordance index matrix

By equation (11), the preference of uncertainty can be calculated:

$$
\bar{d}=\frac{\sum_{g=1}^{z} \sum_{h}^{z} r(g, h)}{z(z-1)}
$$

Using the discordance index discussed above, the discordance index matrix $(\mathrm{F})$ is known by:

$\left\{\begin{array}{lll}u(g, h)=1 & \text { if } & d(g, h) \leq \bar{r} \\ u(g, h)=0 & \text { if } & d(g, h)>\bar{r}\end{array}\right.$

Step 9: Determine net primary and secondary value

Consider $\mathrm{c}_{a}$ and $\mathrm{d}_{a}$ as net primary and net secondary value respectively. $\mathrm{c}_{a}$ sums together the number of alternatives. The $\mathrm{c}_{a}$ is given by:

$$
c_{a}=\sum_{h=1}^{q} v_{(g, h)}-\sum_{h=1}^{q} v_{(h, g)}
$$

$\mathrm{d}_{\mathrm{a}}$ is used to resolve the number of secondary ranking the choices:

$$
d_{a}=\sum_{h=1}^{q} r_{(g, h)}-\sum_{h=1}^{q} d_{(h, g)}
$$

\section{CASE STUDY}

The case study is conducted in one of the leading printing firm in India about the waste management. The reports were obtained from the industries for the last one decade, moreover it is understood that the firms are facing efficiency-based problems throughout the year. Due to the risks involved in this firm the works get deferred. This leading private printing firm in India is known for their reputation and their annual revenue not less than 75 crores. In the usual venture of the organisation, nearly 200 regular and 125 incidental employees are involved. It is significant to examine the factors akin to waste management, for the meaningful operation of waste management. This practice will definitely help the practitioners and managers.

\section{RESULT AND DISCUSSIONS}

The factors for waste management in printing industries are assessed by using elimination and choice translating reality technique. There are many decision-making methodologies for the analysis of factor, we have selected ELECTRE-I methodology because of its interdependence among factors. This ELECTRE-I methodology assess the criteria depending on the inter-related factors and the influence of one factor on other factor. Here, we have selected 7 factor which effects the waste management in printing industries. These factors are selected based on the literatures available on the waste management in printing industries. Generally, in the printing industries, the manufacturers face challenging issues related to the waste management. This paper focuses on assessing the printing industries based on the 7 factors on the influence they possess on the waste management. From the results Total Primary Values and Total Secondary Values can be used to get the results of assessing that which industries has good waste management and which has bad waste 
management. According to figure out the total primary and total secondary expenses for each industry, the assessing results are figured in Table 3 . Table 3 compares the staging of each waste management factor with the total primary and total secondary expenses. The figure out results of the total primary expenses show that Industry 3 have the maximum value in primary values, which is the finest in waste management. On the other hand, assessing the printing industries of waste management based on the total secondary expenses, Industry 2 finished top, while Industry 3 positioned last. Based on the rumination of ELECTRE I, the secondary values are to be focused. Where Industry 3 has a low value in secondary expenses, to increase their efficiency in waste management, we give suggestions that are follows.

- Safe disposal of waste

- Proper house keeping

- Permanent ware houses

- Proper treatment for removing the waste

- Based on the rules of

- 'Ministry of health', the waste management processes should be handled.

TABLE- III. Assessing results of printing industries

\begin{tabular}{|c|c|c|c|c|}
\hline & $\begin{array}{c}\text { Total } \\
\text { Primary } \\
\text { Values }\end{array}$ & $\begin{array}{c}\text { Ranking } \\
\text { of Total } \\
\text { Primary } \\
\text { Values }\end{array}$ & $\begin{array}{c}\text { Total } \\
\text { Secondary } \\
\text { Values }\end{array}$ & $\begin{array}{c}\text { Ranking } \\
\text { Of Total } \\
\text { Secondary } \\
\text { Values }\end{array}$ \\
\hline Industry 1 & -0.1436 & 4 & 0.5822 & 2 \\
\hline Industry 2 & 0.1537 & 2 & 0.6993 & 1 \\
\hline Industry 3 & 0.1738 & 1 & 0.4459 & 4 \\
\hline Industry 4 & 0.0417 & 3 & 0.5630 & 3 \\
\hline
\end{tabular}

\section{CONCLUSION}

From this study, it is observed that the effects of the mentioned factors have played an important role in waste management in printing industries, where industries are looking for new methods and innovative techniques to improve their self. The conclusion of this paper is that the waste management in printing industry can be assessed accurately using MCDM method. Initially, we accept linguistic rating method to calculate the weights of waste management factors. To rank the risk factors, ELECTRE-I methodology is used. The proposed technique in this paper presents assorted choices for officials and the specialist employed in printing industries. Not only for the printing industries the results will be helpful, but also other industries can try these results and increase their productivity.

\section{ANNEXURE}

Table- IV: The importance weights by linguistic rating method

\begin{tabular}{|l|l|l|l|}
\hline S. No & \multicolumn{1}{|c|}{$\begin{array}{c}\text { Waste Management } \\
\text { Factors }\end{array}$} & Weight & Rank \\
\hline 1 & Paper waste & 0.2335 & 1 \\
\hline 2 & Ferrous waste & 0.1364 & 3 \\
\hline 3 & Chemical waste & 0.1893 & 2 \\
\hline 4 & Film waste & 0.0935 & 4 \\
\hline 5 & Foils waste & 0.0652 & 6 \\
\hline 6 & PVC waste & 0.0701 & 5 \\
\hline 7 & Adhesive waste & 0.0625 & 7 \\
\hline
\end{tabular}

Table- V: The values of waste management factors by decision makers

\begin{tabular}{|l|l|l|l|l|l|l|l|}
\hline & $\mathrm{FAC}_{1}$ & $\mathrm{FAC}_{2}$ & $\mathrm{FAC}_{3}$ & $\mathrm{FAC}_{4}$ & $\mathrm{FAC}_{5}$ & $\mathrm{FAC}_{6}$ & $\mathrm{FAC}_{7}$ \\
\hline $\mathrm{K} 1$ & 1 & 3 & 4 & 2 & 5 & 4 & 3 \\
\hline $\mathrm{K} 2$ & 2 & 4 & 3 & 5 & 1 & 3 & 4 \\
\hline $\mathrm{K} 3$ & 4 & 5 & 1 & 4 & 2 & 1 & 5 \\
\hline $\mathrm{K} 4$ & 5 & 2 & 2 & 3 & 4 & 2 & 1 \\
\hline
\end{tabular}

Normalized and Weighted matrix

\begin{tabular}{|c|c|c|c|c|c|c|c|}
\hline \multirow{4}{*}{$X=$} & \multirow{2}{*}{$\begin{array}{l}0.1474 \\
0.2949\end{array}$} & \multirow{2}{*}{0.4082} & 0.7303 & 0.2722 & 0.7372 & 0.7303 & 0.4201 \\
\hline & & & 0.5477 & 0.6804 & 0.1474 & 0.5477 & 0.5601 \\
\hline & 0.5898 & 0.6804 & 0.1826 & 0.5443 & 0.2949 & 0.1826 & 0.7001 \\
\hline & 0.7372 & 0.2722 & 0.3651 & 0.4082 & 0.5898 & 0.3651 & 0.1400 \\
\hline & 0.0344 & 0.0557 & 0.1382 & 0.0255 & 0.0481 & 0.0512 & 0.0263 \\
\hline & 0.0689 & 0.0742 & 0.1037 & 0.0636 & 0.0096 & 0.0384 & 0.0350 \\
\hline & 0.1377 & 0.0928 & 0.0346 & 0.0509 & 0.0192 & 0.0128 & 0.0438 \\
\hline & 0.1721 & 0.0371 & 0.0691 & 0.0382 & 0.0385 & 0.0256 & 0.008 \\
\hline
\end{tabular}

Concordance Interval Matrix

$C=\left[\begin{array}{cccc}- & 0.3246 & 0.3246 & 0.5235 \\ 0.4634 & - & 0.2594 & 0.5518 \\ 0.5259 & 0.4976 & - & 0.2924 \\ 0.3270 & 0.2987 & 0.5581 & -\end{array}\right]$

Discordance Interval Matrix

$D=\left[\begin{array}{cccc}- & 0.9896 & 0.9971 & 1 \\ 1 & - & 0.9957 & 0.3333 \\ 1 & 1.4999 & - & 0.0479 \\ 0.4045 & 0.5397 & 1 & -\end{array}\right]$

Net Secondary Values

$D_{1}=\sum_{b=1}^{4} d_{1 b}-\sum_{b=1}^{4} d_{b 1}=0.5822$

D2 $=0.6993$

D3 $=0.4459$

D4 $=0.5630$

Net Primary Values

$c_{1}=\sum_{b=1}^{4} c_{1 b}-\sum_{b=1}^{4} c_{b 1}=-0.1436$

$\mathrm{C} 2=0.1537$

$\mathrm{C} 3=0.1738$

$\mathrm{C} 4=0.0417$

APPENDIX. Questionnaire

Note: To assess factors affecting waste management in printing industries, as a segment of this project works survey is physique for the motive of performing an audit among the professionals. The data that are collected will be only used for academic purpose only. At any point of time the data gained from the survey will not be shared with others. The data gathered will not be confessed in any publishing and as well as the challenger in the same area. We will authentically acknowledge for contributing your valuable time to give an appraisal for this project work. Your responsibility will extremely relief us to 
achieve the decisive targets of my project work. (Table 2). Please give appraisal that you perceive applicable for several elements (see table 2)

\begin{tabular}{|c|c|c|c|c|c|c|c|}
\hline $\begin{array}{c}\text { Waste } \\
\text { manageme } \\
\text { nt factors }\end{array}$ & $\begin{array}{c}\text { FAC } \\
1\end{array}$ & FAC & FAC & FAC & FAC & FAC & FAC \\
6 & 4 & 5 & 6 & 7 \\
\hline $\begin{array}{c}\text { Paper } \\
\text { waste(FA } \\
C_{1} \text { ) }\end{array}$ & & & & & & & \\
\hline $\begin{array}{c}\text { Ferrous } \\
\text { waste } \\
\left(\text { FAC }_{2} \text { ) }\right.\end{array}$ & & & & & & & \\
\hline $\begin{array}{c}\text { Chemical } \\
\text { waste(FA } \\
C_{3} \text { ) }\end{array}$ & & & & & & & \\
\hline $\begin{array}{c}\text { Film waste } \\
\left(\mathrm{FAC}_{4} \text { ) }\right.\end{array}$ & & & & & & & \\
\hline $\begin{array}{c}\text { Foils waste } \\
\left(\mathrm{FAC}_{5} \text { ) }\right.\end{array}$ & & & & & & & \\
\hline $\begin{array}{c}\text { PVC waste } \\
\left(\mathrm{FAC}_{6} \text { ) }\right.\end{array}$ & & & & & & & \\
\hline $\begin{array}{c}\text { Adhesive } \\
\text { waste } \\
\left(\text { FAC }_{7} \text { ) }\right.\end{array}$ & & & & & & & \\
\hline
\end{tabular}

Profile of the expert:

1. Name:

2. Experience in printing industries (in years): .......

3. Name of organization:

4. Current position in the organization:

5. Mobile no \& Email:

We are grateful for your moment and discipline in filling this quest

\section{REFERENCES}

1. H. Haider, R. Sadiq and S. Tesfamariam, "Selecting performance indicators for small and medium sized water utilities: Multi-criteria analysis using ELECTRE method," Urban Water Journal, Vol. 12(4), 2015, 305-327.

2. K. Govindan and M. B. Jepsen, "Supplier risk assessment based on trapezoidal intuitionistic fuzzy numbers and ELECTRE TRI-C: a case illustration involving service suppliers," Journal of the Operational Research Society, Vol. 67(2), 2016, 339-376.

3. J. Pang, G. Zhang and G. Chen, "ELECTRE I Decision Model of Reliability Design Scheme for Computer Numerical Control Machine," JSW, Vol. 6(5), 2011, 894-900.

4. M. Petrović, N. Bojković, M. Stamenković and I. Anić, "Supporting performance appraisal in ELECTRE based stepwise benchmarking model," Omega, Vol. 78, 2018, 237-251.

5. H. Uysal and K. Yavuz, "Selection of Logistics Centre Location via ELECTRE Method: A Case Study in Turkey," International Journal of Business and Social Science, Vol. 5(9), 2014.

6. M. C. Wu and T. Y. Chen, "The ELECTRE multicriteria analysis approach based on Atanassov's intuitionistic fuzzy sets," Expert Systems with Applications, Vol. 38(10), 2011, 12318-12327.

7. X. Yu, S. Zhang, X. Liao and X. Qi "ELECTRE methods in prioritized MCDM environment," Information Sciences, Vol. 424, 2018, 301-316.

8. M. Alemi, H. Jalalifar, G. R. Kamali and M. Kalbasi, "A mathematical estimation for artificial lift systems selection based on ELECTRE model," Journal of Petroleum Science and Engineering, Vol. 78(1), 2011, 193-200.

9. A. S. Costa, K. Govindan and J. R. Figueira, "Supplier classification in emerging economies using the ELECTRE TRI-nC method: A case study considering sustainability aspects," Journal of Cleaner Production, Vol. 201, 2018, 925-947.

10. J. Dodangh, M. Mojahed and V. Nasehifar, "Ranking of Strategic Plans in Balanced Score card by Using Electre Method,"
International Journal of Innovation, Management and Technology, Vol. 1(3), 269

\section{AUTHOR PROFILE}

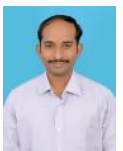

Dr.S.Bathrinath is an Associate Professor in the Department of Mechanical Engineering, Kalasalingam Academy of Research and Education, Krishnankoil, Tamilnadu, India. His current area of research includes multi-criteria decision making, scheduling \& optimization, soft computing and Artificial intelligence. He has published a number of papers in journal of national/international epute and presented a number of papers in various conferences/symposia in India and abroad. He is presently guiding a number of master/doctoral research scholars. Dr.S.Bathrinath is the corresponding author and can be contacted at: bathri@gmail.co

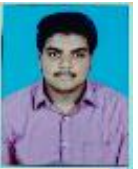

A.K.N.Vignesh is currently doing final year B.E(MECH) in kalasalingam academy of research and education, Krishankovil,,Tamilnadu,India.

S.Venkatesh is currently doing final year B.E(MECH) in kalasalingam academy of research and education, Krishankoil, Tamilnadu, India.

R.Satheshkumar is currently doing final year B.E $(\mathrm{MECH})$ in kalasalingam academy of research and education, krishnankoil, Tamilnadu, India 